\title{
LOS MEDIOS EN HISPANOAMÉRICA EN EL CONTEXTO DE LA COMUNICACIÓN GLOBAL (título original: MEDIA W HISPANOAMERYCE W PERSPEKTYWIE KOMUNIKOWANIA GLOBALNEGO)
}

\section{Radoslaw Sajna: Wydawnictwo Uniwersytetu Kazimierza Wielkiego, Bydgoszcz 2013.}

\section{Andrzej Tarczynski}

Los tiempos recientes nos hacen conscientes más que antes que el arte de la narración acerca ciertos acontecimientos, muchas veces ejerce influencia mayor y deja las huellas más profundas que esos acontecimientos como tales. La forma de comunicación crea un universo, impone claves de la interpretación y contribuye en mucho para establecer cierta forma de dominación de la realidad. Como se expresaron, hace unos años, Tomás Eloy Martínez y Susana Rotker: "Narrar es conquistar. Narrar es escribir la ley, la legalidad y la legitimidad. Era encontrar un discurso que ordenaba lo real, y al ordenarlo, establecía las fuentes de la autoridad que lo regía"12. Antes - durante décadas y siglos enteros - esas funciones desempeñaban los relatos históricos, mientras que de forma contemporánea con mayor frecuencia los medios de comunicación emprenden la tarea de formar la realidad narrada y modelar las categorías del pensamiento del público. El estudio del investigador polaco Radoslaw Sajna "Los medios en Hispanoamérica en el contexto de la comunicación global' pretende ser la síntesis teórica de la presencia, funcionamiento e influencia social de los medios de comunicacón en los países hispanoamericanos, percibido y analizado en el marco conceptual de la globalización.

\footnotetext{
${ }^{1}$ Catedrático de sociología en la Univesidad de Kazimierz Wielki de Bydgoszcz(Polonia). Especializado en socología histórica; ha dedicado la mayoría de sus estudios publicados al área de Hispanoamérica (influencia de la conquista y aportación española a la realidad social y tradición de Hispanoamérica).
} 
La estructura del libro es clara y lógica - el autor parte de algunas cuestiones generales acerca del sentido mismo de comunicación global y sus rasgos fundamentales, para pasar - en dos capítulos siguientes - al vasto panorama de medios de comunicación dentro del marco hispanoamericano y problemas particulares que hacen huellas notables en el periodismo en esa región (hay que mencionar que el autor - aunque algunas veces alude los hechos concernientes al Brasil - en general limita y ajusta sus investigaciones y análisis a la comunidad lingüística y cultural de Hispanoamérica). El lector puede seguir los orígenes y puntos de base como así las vicisitudes de diferentes ramas del mundo mediático en países americanos de habla española (así que diferentes párrafos están dedicados p. ej. a la prensa, sistemas televisivos, medios alternativos, pero también al papel desempeñado por medios y periodistas mismos en el avance de democracia o limitaciones y obstáculos con que - no pocas veces - tienen que enfrentar los representantes del mundo de medios de comunicación, tanto tradicionales como los llamados medios nuevos).

La segunda parte del estudio aquí relatado - que la componen capítulos cuarto y quinto - está concentrada al torno de casos particularidades del uso de ciertos medios de comunicación para presentar/imponer la visión del mundo (en sus dimensiones políticas y sociales) por concretas fuerzas políticas e ideológicas. Son los casos del funcionamiento de canales de transmisión, en sociedades no democráticas (Cuba) o aparentemente democráticas (Venezuela después del ascenso al poder de Hugo Chávez). Los fragmentos apartes - no menos interesantes - se refieren al uso del internet por los representantes, simpatizantes o partidarios de algunos los llamados "nuevos" movimientos sociales (como neozapatistas en México), la posición de Hispanoamérica en época de la comunicación multimediática, más oportunidades y dilemas que esa ocasiona, así como la presencia de la problemática ecológica y medioambiental en escogidos canales de comunicación hispanoamericanos.

El autor aclarando la específica de la comunicación hoy posible, a través del uso de tecnologías avanzadas (es decir en la época del internet), se refiere al concepto de la "comunicación cuántica" - los usuarios de la red global reciben, transmiten y crean las puequeñas cantidades de información que - bien sumadas - generan cierta forma de "energía de comunicación". Esos fenómenos ponen fin a las clásicas - y aún anticuadas hoy 
- teorías de la comunicación masiva que implicaban la existencia de público reducido a las masas pasivas e inermes frente a los poderosos centros de emisión que, por su parte, eran capaces de moldear la forma de pensar y sentir del público casi a su antojo. Esta imagen debe ceder el paso a la otra realidad, donde los movimientos sociales y generados por sus actividades cambios sociales y estructurales, resultan ser efectos de intercambio de información y opiniones ("cuantos de energía comunicativa") entre centenares de internautas (p. 91-93). Por otra parte, las últimas décadas están marcadas en el mundo de comunicaciones - de las tendencias tales como concentración, emergencia de poderosos consorcios mediáticos y grupos del capital transnacional que pretenden conquistar y dominar los mayores áreas posibles. En consecuencia, podemos observar los roces e interferencias entre esos dos sistemas de comunicación - el de grandes jugadores (consorcios multimediáticos) y el de medios alternativos. Según opinión del autor del libro referido, la Hispanoamérica de hoy debe ser concebida como el terreno de coexistencia pero también de la competición de aquellos dos sistemas (p. 410-411).

Uno de los motivos que reaparecen a través del texto es la cuestión de conflicto tomado en diferentes posibles formas y dimensiones - (sirviéndose también de paradigmas de clásicos de sociología como L. Coser), como el prisma con que podemos mejor divisar y entender las particularidades de visiones creadas y/o establecidas por los que manejan el aparato de medios de comunicación o simplemente los usuarios de internet. No pocas veces el autor muestra como la fraseología antiimperialista, a menudo adaptada y utilizada en el discurso sobre los medios en Hispanoamérica, sirve para cubrir sus propios complejos y deficiencias de los que se recurren a conceptos de tal tipo. A la vez nos permite ver las desigualdades y desproporciones verdaderas en cuanto al intercambio de unidades de información en el marco global, que en sus resultados más profundos, contribuye en mucho a la creación de imágenes estereotipados y fortalecimiento de desigualdad en poder de transmisión de mensajes e ideas (he aquí el caso de telenovelas latinoamericanas a las que el autor dedica un párrafo entero, p. 226-236).

El estudio tiene carácter analítico - pretende ser la presentación de resultados de investigaciones propias del autor y evita - afortunadamente - las distorsiones ideológicas con que a veces están contagiadas los textos dedicados a elaborar la diagnosis de un 
determinado fenómeno o proceso social que atraen mayor atención de expertos y comentaristas. Muchas veces los fragmentos de los comunicados, citados por autor, sirven como bastantes evidencias de fuentes ideológicas e inspiraciones o los más concretos intereses que se esconden detrás de las palabras como los recursos usados en la narración transmitida hacia destinatarios presumidos.

Otra cosa que el lector concienzudo puede a veces encontrar algunos pasajes o detalles dudosos, aunque esos no se refieren a la material principal del libro sino al contexto social, histórico etc. Así, aparece, tal vez por error de imprenta, la fecha errónea del establecimiento del sistema republicano en el Brasil (p.116), la información extraviada de que el punto final de la ruta de famosa navegación de Vasco da Gama a la India era Calcutta, en lugar de Calicut en la costa de Malabar (p. 132). En la página 354 el autor dice que la capital colombiana en los tiempos remotos llevaba nombre Santafé de Bogotá, inconsciente de que ese histórico, pleno nombre capitalino fue restablecido de manera formal hace poco tiempo.

Cierto mal entendimiento puede surgir de una frase (p. 141) donde el autor hace entender al lector de que la llamada teología de liberación apareció en el mundo intelectual con la publicación de la encíclica Rerum novarum por el papa León XII en 1891, aunque ese texto papal fue en realidad el primer caso de entablar por la Iglesia Católica lo que en el lenguaje de la época se llamaba "cuestión social" o "cuestión obrera", mientras que el surgimiento de teología de libertad ordinariamente se asocia con la actividad de Gustavo Gutiérrez y publicación de su libro así titulado más de setenta años más tarde. Algo dudosas e inquietantes son aseveraciones del autor de que los estados de Hispanoamérica no participaban de manera activa en ambas guerras mundiales, aunque Argentina colaboraba con Alemania durante segunda guerra mundial (p. 128). Observemos aquí que el autor en este caso se deja llevar por la visión creada por los norteamericanos que reprocharon las autoridades argentinas - acabada ya la contienda mundial - de haber favorecer a Alemania nazi, sólo para "castigar" así los argentinos por la postura neutral de Argentina durante el conflicto. Añadamos aquí que, en contra de lo que parece ser evidente, existe un caso de la participación activa uno de los países de Hispanoamérica, aunque en dimensiones simbólicas, en acciónes bélicas de Segunda Guerra Mundial - aviadores mexicanos de dos escuadrillas luchaban contra los japoneses en la etapa final de la contienda, operando del suelo filipino. 
Podemos también poner en duda la opinión de que la revolución cubana no fue y no sigue siendo sólo una iniciativa local sino el elemento de la rivalidad en la escala mundial ( $p$. 264) - en sus orígenes y particularidades, de verdad fue un acontecimiento local, sin embargo después se ha vuelto un elemento de cierta importancia dentro del marco de política de grandes potencias mundiales, colocando el relativamente pequeño país caribeño en el centro de rivalidad ideológica y política de la época de guerra fría. Si el autor (p. 394395) declara de que Argentina goza de una situación geográfica que la hace el más diferenciado en toda Hispanoamérica, en cuanto a las características naturales, esa opinión puede satisfacer al orgullo nacional de los argentinos mismos, pero ¿es una verdad incuestionable?

A pesar de algunos defectos de poca importancia, como los arriba mencionados, el libro de Radoslaw Sajna tiene buen valor teórico y educativo, hace más clara la materia y abre los caminos en la maraña, a la primera vista casi impenetrable, que crean los - ya muy diferenciados, multiformes y polifónicos y cada vez más numerosos y polifacéticos - medios de comunicación del mundo hispánico. Sería muy provechoso e interesante que el lector hispanoamericano tuviera oportunidad de conocer el contenido pleno del libro aquí presentado en su lengua materna y comparar sus propias observaciones, esquemas y modo de interpretación de la realidad analizada con las del investigador polaco. Muchas veces la perspectiva múltiple hace posible comprender el fondo del fenómeno investigado, percibir su influencia y resultados generados, a veces inesperadamente.

Radoslaw Sajna - doctor de ciencias políticas, especialista en teoría de comunicación y sistemas mediáticos. Autor de tres libros y numerosos textos publicados en polaco, inglés y español. Ha impartido conferencias en Granada e Istanbul. Miembro de varias sociedades científicas nacionales e internacionales (IAMCR, IECA). 